\title{
Liver Cancer Emergence Associated with Antiviral Treatment: An Immune Surveillance Failure?
}

\author{
María Reig, MD, $\mathrm{PhD}^{1}$ Loreto Boix, MD, $\mathrm{PhD}^{1}$ Zoe Mariño, MD, $\mathrm{PhD}^{2}$ Ferran Torres, MD, $\mathrm{PhD}^{3}$ \\ Xavier Forns, $\mathrm{MD}, \mathrm{PhD}^{2}$ Jordi Bruix, $\mathrm{MD}, \mathrm{PhD}^{1}$
}

${ }^{1}$ BCLC group. Liver Unit, Hospital Clinic, IDIBAPS, University of Barcelona, Centro de Investigación Biomédica en Red de Enfermedades Hepáticas y Digestivas (CIBERehd), Barcelona, Spain

2 Liver Unit, Hospital Clinic, IDIBAPS, University of Barcelona, Centro de Investigación Biomédica en Red de Enfermedades Hepáticas y Digestivas (CIBERehd), Barcelona, Spain

${ }^{3}$ Medical Statistics Core Facility, IDIBAPS, Hospital Clinic Barcelona, Spain; Biostatistics Unit, Faculty of Medicine, Universitat Autònoma de Barcelona, Barcelona, Spain

Semin Liver Dis 2017;37:109-118.

\author{
Address for correspondence María Reig, MD, PhD, BCLC group, Liver \\ Unit, Hospital Clinic, IDIBAPS, CIBERehd, University of Barcelona, \\ c/ Villarroel, 170. Escala 11, 4a planta, 08036 Barcelona, Spain \\ (e-mail: mreig1@clinic.ub.es).
}

\begin{abstract}
Keywords

- hepatitis C

- hepatocellular carcinoma

- direct antiviral agents

- incidence

- recurrence

The availability of new direct antiviral agents to safely and effectively treat the hepatitis $C$ virus represents a major advancement in the field of liver disease. Most patients achieve complete viral eradication sustained over time. In addition, the administration of these new agents is safe and does not require limitations when liver function is impaired. Some now expect the hepatitis $C$ virus to be completely eradicated in a few years. However, not all data are positive. In April 2016, we published a cohort study suggesting that viral eradication with the new agents could be associated in time with the emergence of recurrent cancer sites in patients previously treated for hepatocellular carcinoma. In this review, we update our report and summarize the data provided in recent publications. We also speculate about the mechanisms for cancer emergence and stress the need for further studies.
\end{abstract}

The management of patients with hepatitis $\mathrm{C}$ virus (HCV) was revolutionized by interferon- (IFN-) free treatments with direct antiviral agents (DAAs) due to their efficacy in terms of sustained virological response and also their excellent safety profile during treatment. ${ }^{1}$ This major advancement has been associated with an increase in the number of patients treated, some with more advanced liver dysfunction than patients treated with IFN-based regimes. Special populations such as patients with hepatocellular carcinoma (HCC) either successfully treated or still active, which may not have been included in the major studies assessing the antiviral effectiveness of DAAs $^{2-13}(-$ Table 1$)$, have since been treated with the new agents. The assumption was that HCV eradication would translate into a reduced incidence of de novo tumors in $\mathrm{HCV}$ patients and that the recurrence of HCC after initial success would also be reduced through $\mathrm{HCV}$ cure. ${ }^{14}$ This positive expectation was very appealing both for patients-who had been awaiting an effective and safe treatment option-and for physicians, who had seen their HCV patients transition from chronic hepatitis to cirrhosis and ultimately to end-stage liver failure and/or cancer. The success of the new agents has been so striking that the current treatment guidelines of the European Association for the Study of the Liver (EASL) ${ }^{1}$ recommend treating almost all HCV patients, including those with concomitant or prior HCC or any other cancer, with these new agents. This recommendation contrasts with the current controversy about a potential association between antiviral treatment and the emergence of HCC either de novo or as a recurrence: $A$ higher incidence and more aggressive profile have been registered in some studies. In our April 2016 ${ }^{15}$ report we described an increased incidence of HCC recurrence associated in time with antiviral treatment in patients who had been successfully treated for HCC and who had been free of disease for varied periods.

In this review, we summarize and update our data while simultaneously reviewing the results that have been 
Table 1 Inclusion-exclusion criteria related to HCC and description of US screening evaluation in the pivotal studies showing the benefit of DAAs

\begin{tabular}{|c|c|c|c|c|}
\hline Study & $\begin{array}{l}\text { Clinical trial } \\
\text { number }\end{array}$ & $\begin{array}{l}\text { HCC inclusion } \\
\text { criteria }\end{array}$ & $\begin{array}{l}\text { HCC exclusion } \\
\text { criteria }\end{array}$ & $\begin{array}{l}\text { US } \\
\text { screening of HCC }\end{array}$ \\
\hline Poordad et al, $2013^{2}$ & NCT01306617 & - & - & No \\
\hline Ferenci et al, $2014^{3}$ & $\begin{array}{l}\text { NCT01767116 } \\
\text { NCT01833533 }\end{array}$ & - & - & No \\
\hline Feld et al, $2014^{4}$ & NCT01716585 & - & - & No \\
\hline Kwo et al, $2014^{5}$ & NCT01782495 & $\begin{array}{l}\text { HCC within MC before } \\
\text { LT or without HCC } \\
\text { post-LT for at least } 1 \text { y } \\
\text { Out of MC on the } \\
\text { explanted liver, but } \\
\text { without recurrence for } \\
\text { at least } 2 \text { y } \\
\text { posttransplant. }\end{array}$ & - & No \\
\hline Foster et al, $2015^{6}$ & NCT02201953 & - & Yes & No \\
\hline Curry et al, $2015^{7}$ & NCT02201901 & - & Yes & No \\
\hline Feld et al, $2015^{8}$ & NCT02201940 & - & Yes & No \\
\hline $\begin{array}{l}\text { Sulkowski et al, } \\
2014^{9}\end{array}$ & NCT01359644 & - & - & No \\
\hline Poordad et al, $2014^{10}$ & NCT01704755 & - & $\begin{array}{l}\text { Yes (within } 3 \mathrm{mo} \text { ) or } \\
\text { AFP }>100 \mathrm{ng} / \mathrm{dL}\end{array}$ & US at screening/EOT ${ }^{a}$ \\
\hline Afdhal et al, $2014^{11}$ & NCT01768286 & $\begin{array}{l}\text { Liver imaging within } 6 \\
\text { mo of baseline/day } 1 \\
\text { to exclude HCC in } \\
\text { patients with cirrhosis }\end{array}$ & Yes & No \\
\hline $\begin{array}{l}\text { Jacobson et al, } \\
2013^{12}\end{array}$ & NCT01542788 & - & Yes (within $3 \mathrm{mo}$ ) & $\begin{array}{l}\text { US at screening/EOT/ } \\
\text { premature DC }\end{array}$ \\
\hline Lawitz et al, $2013^{13}$ & $\begin{array}{l}\text { NCT01497366 } \\
\text { NCT01641640 }\end{array}$ & $\begin{array}{l}\text { Liver imaging within } \\
6 \text { mo of baseline/day } \\
1 \text { to exclude HCC in } \\
\text { patients with } \\
\text { cirrhosis }\end{array}$ & - & US at screening/EOT ${ }^{\mathrm{a}}$ \\
\hline
\end{tabular}

Abbreviations: AFP, alpha-fetoprotein; DC, DAA discontinuation; DDA, direct-acting antiviral agents; EOT, end of treatment; HCC, hepatocellular carcinoma; LT, liver transplantation; MC, Milan Criteria; US, ultrasound.

${ }^{a}$ Subjects with a historical negative liver ultrasound, CT or MRI (within 3 months prior to screening) are not required to have a screening ultrasound performed.

reported by other groups reinforcing or denying the association between HCC emergence and DAA therapy. We also speculate about the mechanisms for such an event and raise the need for major clinical and laboratory research efforts.

\section{The Cohort Study that Raised the Signal}

The main clinical and tumor characteristics of the patients described in our 2016 report ${ }^{15}$ are provided in -Table 2. The retrospective cohort included 124 patients from four Spanish hospitals; 105 presented HCC under complete response before starting DAAs. After excluding patients with potential confounding factors, we retained 77 of the cohort. Mean age was 66 years and $69 \%$ were male. The baseline Barcelona Liver Cancer Clinic (BCLC) stage at HCC treatment was BCLC-0/A $(n=75)$ and BCLC-B $(n=2), 89 \%$ received resection/ablation. Up to $94.7 \%$ achieved sustained virological response. After a median follow-up of 8.2 months since the start of DAA therapy, the rate of recurrence was $27.3 \%(21 / 77)$.

-Fig. 1 illustrates the relevant time points of the cohort from HCC treatment (with achievement of complete response without any suspicion of additional tumor sites at imaging) to antiviral treatment initiation and the time to recurrence or last follow-up. The initial data raised the pharmacovigilance alarm; hence, we have now incorporated data on additional recurrences.

In addition to the recruitment of additional patients, we have also been able to characterize the evolution of the recurrences and their response to therapy. In - Table 2, the tumor stage at first treatment, stage at recurrence, and the treatment applied and its success are given. As shown, although most recurrences were apparently able to be effectively treated, the evolution has been dismal in most instances. Six of the 19 patients who received HCC treatment at recurrence presented progression within the next 6 months; a large proportion transitioned into 
Table 2 Characterization of the evolution of the recurrences and their response to HCC therapy in the 21 patients with recurrence in September 2016

\begin{tabular}{|c|c|c|c|c|c|}
\hline \multirow{2}{*}{$\begin{array}{l}\text { Before DAA } \\
\text { BCLC stage at } \\
\text { first HCC } \\
\text { treatment }\end{array}$} & \multicolumn{5}{|c|}{ HCC evolution post-DAA } \\
\hline & $\begin{array}{l}\text { BCLC stage at } \\
\text { HCC recurrence } \\
\text { post-DAA }\end{array}$ & $\begin{array}{l}\text { Recurrence } \\
\text { treatment }\end{array}$ & $\begin{array}{l}\text { Time from } \\
\text { recurrence to } \\
\text { progression } \\
\text { (months) }\end{array}$ & $\begin{array}{l}\text { BCLC at } \\
\text { HCC progression }\end{array}$ & $\begin{array}{l}\text { Progression } \\
\text { treatment }\end{array}$ \\
\hline$A$ & $A$ & LT & & & \\
\hline 0 & $A$ & Percutaneous & 6.6 & B & TACE \\
\hline$A$ & $A$ & Percutaneous & & & \\
\hline$A$ & $A$ & Resection & & & \\
\hline 0 & $A$ & Resection & 2.7 & $C$ & Sorafenib \\
\hline 0 & C & Sorafenib & & & \\
\hline$A$ & $A$ & Percutaneous & 5.7 & $C$ & Sorafenib \\
\hline$A$ & A & TACE & & & \\
\hline A & $A$ & Percutaneous & 6.6 & $A$ & $\mathrm{LT}$ \\
\hline$A$ & A & Percutaneous & & & \\
\hline$A$ & $C$ & Sorafenib & & & \\
\hline$A$ & B & RE & & & \\
\hline B & $B$ & TACE & 1 & $\mathrm{C}$ & Sorafenib \\
\hline$A$ & $A$ & Percutaneous & & & \\
\hline$A$ & $C$ & Sorafenib & 6.8 & $C 2^{\mathrm{a}}$ & Regorafenib \\
\hline$A$ & $A$ & LT & & & \\
\hline$A$ & D & BSC & & & \\
\hline$A$ & $A$ & LT & & & \\
\hline 0 & $\mathrm{D}$ & BSC & & & \\
\hline B & $C$ & Sorafenib & & & \\
\hline$A$ & D & BSC & & & \\
\hline
\end{tabular}

Abbreviations: BCLC, Barcelona Liver Cancer Clinic staging; BSC, best supportive care; DAA, direct antiviral agents; HCC, hepatocellular carcinoma; LT, liver transplantation; percutaneous, percutaneous treatment; TACE, transarterial chemoembolization.

Note: Boldface values mean that only two patients were BCLC-B before starting DAA and patients with fastest and unexpected HCC evolution after starting DAA.

${ }^{\mathrm{a}} \mathrm{BCLC}$ up on progression classification. ${ }^{42}$

end stage. As a result, only 8 of 21 (38\%) patients could effectively benefit from resection/ablation/liver transplantation, whereas almost half $(10 / 21,47.6 \%)$ received systemic/locoregional treatment and 3 of 21 (14\%) patients received best supportive care.

Follow-up of the cohort further confirmed our initial data; furthermore, we found a recurrence pattern that is more aggressive than what is observed in conventional clinical practice and in clinical trials. Even if a direct comparison is not possible between the studies, the pattern of recurrence in the placebo arm of the STORM (Adjuvant Sorafenib for Hepatocellular Carcinoma after Resection or Ablation) trial $^{16}$ (12\% of patients developed extrahepatic recurrence at the end of follow-up) or the one-year HCC-stage-transition estimation from early to advanced stage according to the Ikeda-Markov model ${ }^{17}$ (1.7\% of patients in the whole population and $1.35 \%$ in the group of patients with a similar age as our cohort) seems less aggressive than what we observed in our cohort.

\section{The Emerging Data: Confirming or Refuting}

The publication of our cohort coincided with the presentation of data from Buonfiglioli ${ }^{18}$ et al as a poster at the 2016 annual meeting of EASL. There they also reported an unexpected high recurrence rate in patients with successfully treated HCC. The rate of early HCC recurrence was similar to ours (28.8\%), and both datasets primed the publication of the experiences of several groups around the world. Data about HCC appearance affect two different dimensions: the development of HCC after DAA treatment in patients without a prior history of HCC, and the development of tumor recurrence in patients with a prior history of HCC. ${ }^{19}$ As shown in -Table 3, some of the information is reported in Letters, ${ }^{22-25,31-34}$ and in some instances the data are the results of post hoc analyses of studies in which HCC was not among the initial endpoints. ${ }^{26,30}$ Finally, in other reports, HCC development was an endpoint, but there was no formal 


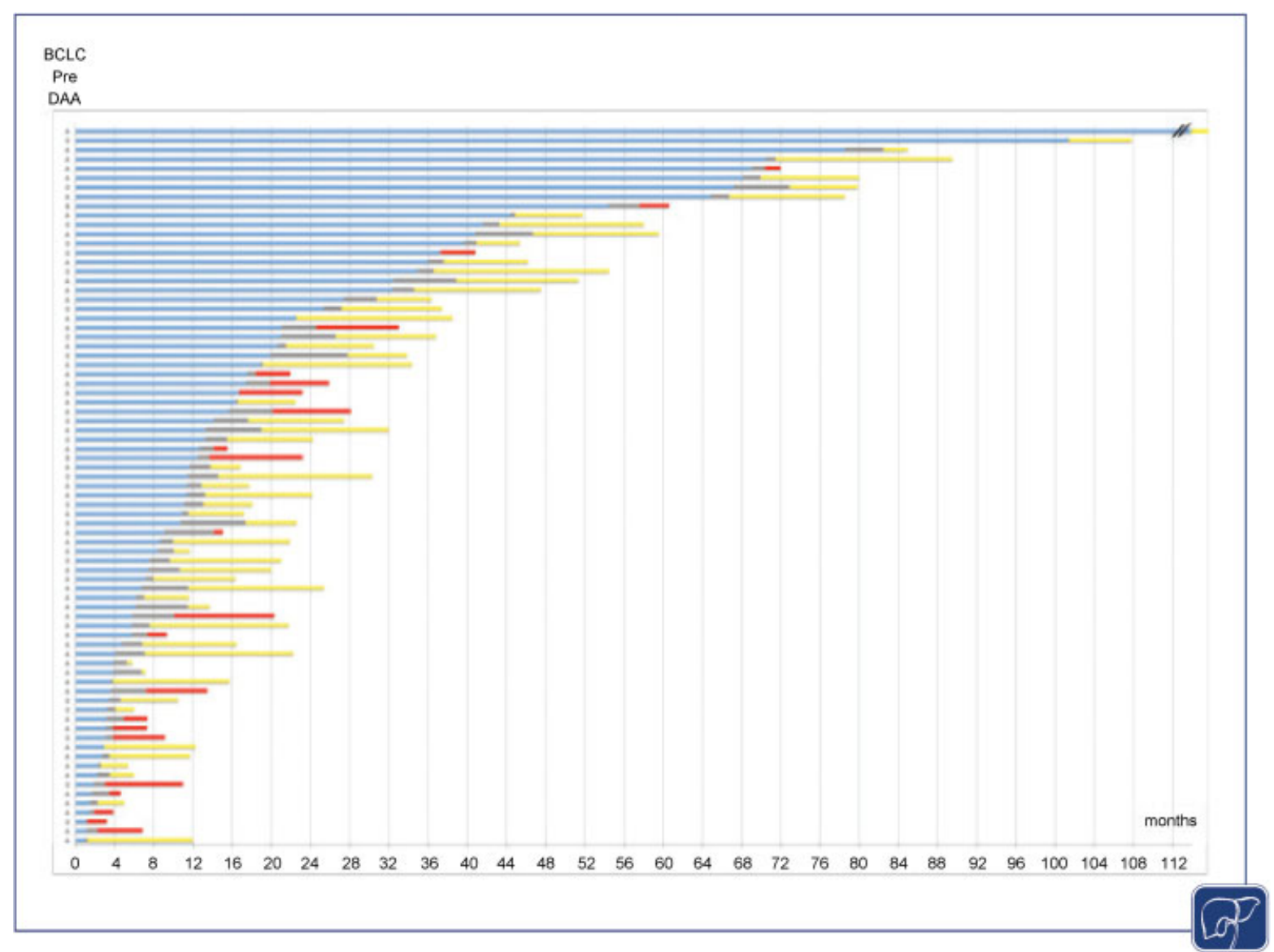

Fig. 1 Time points for radiology evaluation of tumor status. The evolution of each patient is described in three time periods: Blue boxes reflect the time between hepatocellular carcinoma (HCC) treatment and the last assessment of complete response (CR) by imaging. It shows the interval between HCC treatment and the date of the last radiologic evaluation (which confirmed the CR in each patient) prior to direct antiviral agent (DAA) therapy. Gray boxes represent the second time period-time window between last CR assessment and DAA initiation-reflecting the time between the date of the last radiologic confirmation of CR, and the start date of DAA. The last time period depicts HCC evolution after starting DAA, which depends on the outcome of the patients. Red boxes indicate the time between the date of the first dose of DAAs and the date of radiologic tumor progression. Yellow boxes denote the last radiologic evaluation during follow-up in patients without radiologic tumor progression.

adherence to the proper screening strategy every 6 months or the follow-up time may have been too short to reach robust conclusions about incidence. ${ }^{20,21}$

\section{Recurrence of HCC after DAA Treatment}

As commented before, the majority of these publications are Letters without enough data to confirm or refute the alarm. However, the time association between DAA initiation and HCC recurrence was reported in many. As shown in - Table 3, the Letters/articles include less patients than in the Spanish $^{15}$ and Italian cohorts ${ }^{19}$ and/or do not report essential information such as a schedule of the HCC evaluation, the median follow-up time, and/or if HCC was evaluated regularly in their cohort.

An important dataset is available in the French cohort studies of HCV patients under the ANRS (French Agency of Research on AIDS) acronym. ${ }^{26}$ Three cohorts of patients accounting for more than 500 cases have challenged the alarm signal and suggested that the risk did not exist.
Although the sample size is relevant, there are several issues that need clarification. Hepatocellular carcinoma was not an endpoint in two of the cohorts (ANRS CO22 HEPATHERNCT01953458-36 and ANRS CO23 CUPILT cohortNCT01944527-). Thus, if the evaluation of HCC was not part of the prospective collection data at well-defined regular time intervals, underregistration is feasible and the study cannot properly inform about the rate of radiologic recurrence. Hepatocellular carcinoma was an endpoint in the ANRS CO12 CirVir, ${ }^{28,37,38}$ but at the time of the first report they had only 13 patients treated with DAA therapy. ${ }^{26}$ A later update of the CIR-VIR study will be commented in the part devoted to patients without prior HCC. ${ }^{28,38}$

Interestingly, the HCC recurrence in two of the cohorts was reported as HCC recurrence/person-months ${ }^{26}$ to avoid the bias related to the analysis of evolutionary events in a cohort with widely different follow-up times. The timedependent estimated hazard ratio in the ANRS CO22 HEPATHER cohort was 1.21 (95\% confidence interval [CI], 0.62$2.34, p=0.5782$ ), and 0.41 (95\% CI, 0.05-3.08, $p=0.386$ ), in 


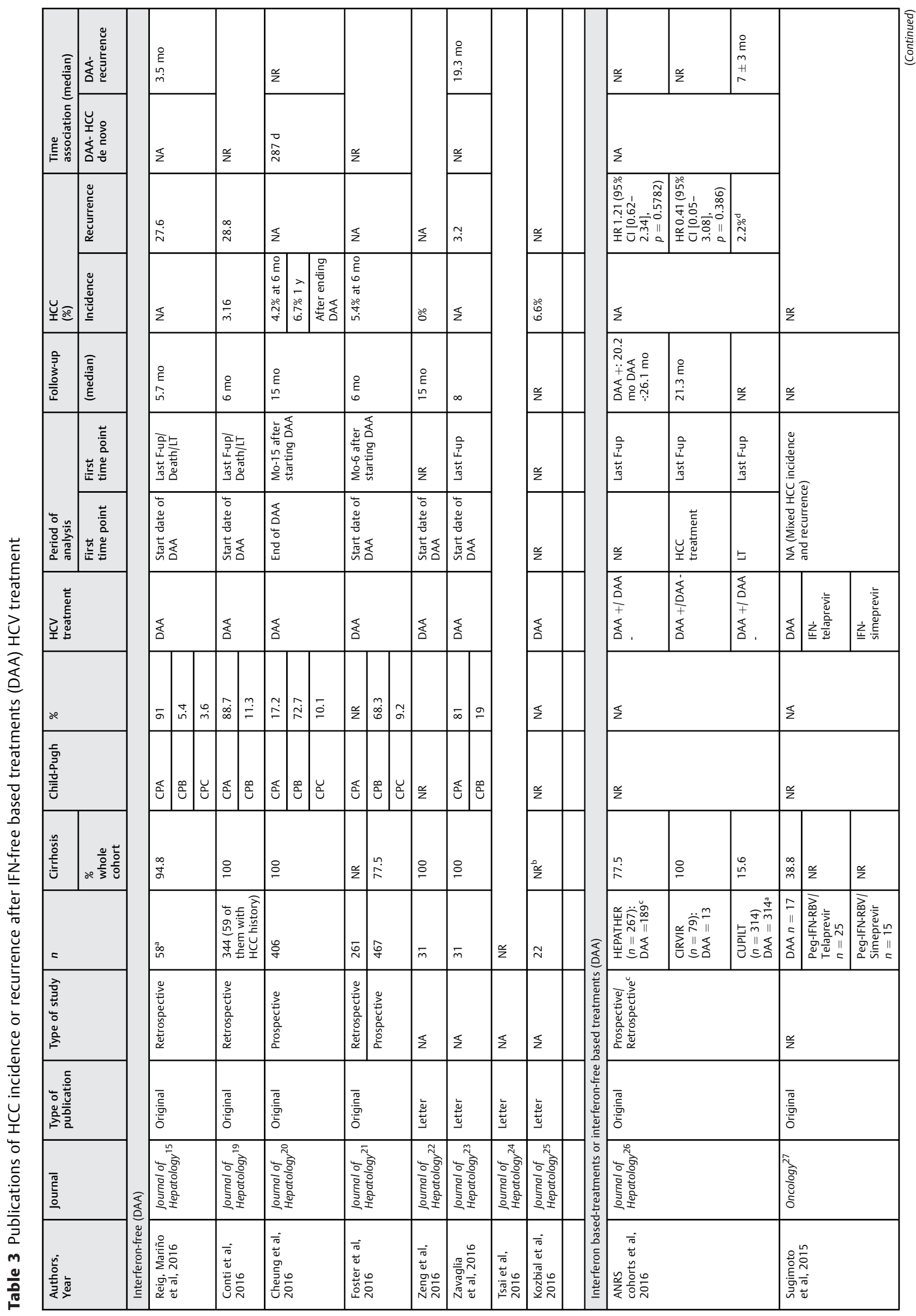




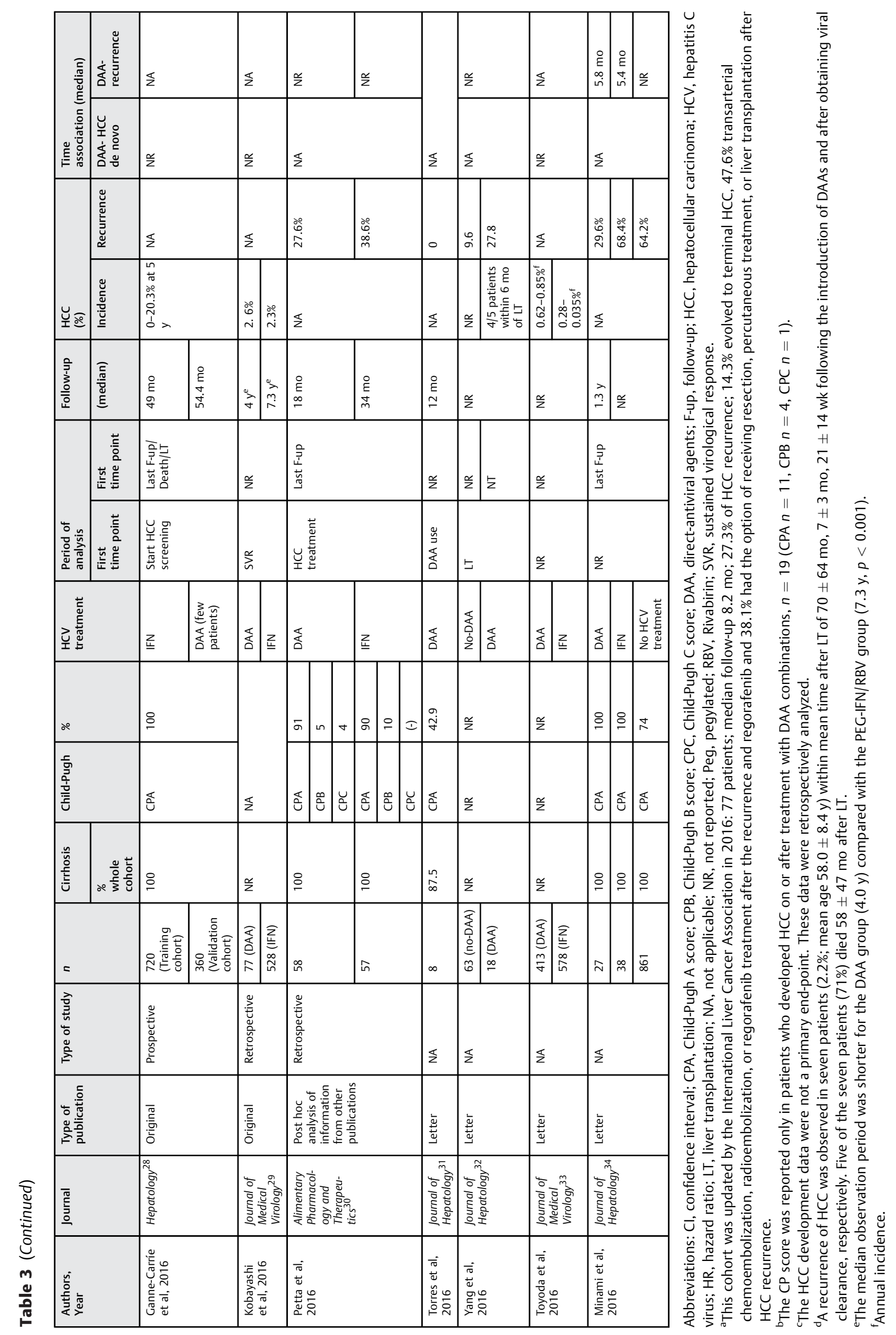


the ANRS CO12 CirVir cohort. Bearing in mind the risk of underregistration, the small number of patients who received DAAs, and the 2.34 and 3.08 upper $95 \% \mathrm{CI}$, these data are not robust enough to rule out an increased recurrence risk.

The Craxi group ${ }^{35}$ in Italy raised a major criticism of the initial data. They extracted data from our study ${ }^{15}$ and used the time of HCC therapy as Time 0 to estimate the incidence of recurrence. This approach is flawed as is their use of a meta-analysis $^{39}$ assessment for any valid comparison. It neglects the evolution of those who died/recurred prior to the availability of DAAs and/or did not receive DAAs for any reason.

Comparing the recurrence rate by using the time from HCC treatment and the last time on complete response reflects a post hoc and data-driven strategy based on the observed data that is known to imply a high risk of bias as the analysis includes both the factor used for the comparison and the selection of the cutoff point.

\section{Development of HCC in Patients without Prior HCC}

The development of HCC was not evaluated in the initial studies that led to registration (-Table 1). ${ }^{2-13}$ Follow-up within the trials was usually 6 to 12 months, and registration of HCC during follow-up was not an endpoint. Thus, HCC surveillance was not part of the mandatory trial assessments. Hence, the current data about HCC incidence after DAA therapy come from cohort studies done after the commercialization of DAA treatment. ${ }^{20,21,40}$ In patients without cirrhosis, the risk of HCC is known to be low; thus, attention has to be given to the information about patients with cirrhosis. One important aspect when assessing the incidence of de novo HCC in patients treated with DAAs is to recall that the profiles of the patients who are treated with these agents are far more advanced that those treated with prior IFN-free regimes. Although most patients with portal hypertension would be excluded from prior options, the safety of DAAs allows their use in patients with portal hypertension and liver decompensation. Because the incidence of HCC is known to increase along the evolution of cirrhosis, any assessment not taking into account this concept would be misleading. The degree of portal hypertension measured as hepatic vein pressure gradient or elastography also stratifies HCC risk within compensated cirrhosis. In addition to this liver-functionrelated predictor, conventional clinical parameters such as male gender, age $>60$ years old, alcohol intake, diabetes, and baseline alpha-fetoprotein serve to identify the population at higher risk. An important prospective cohort has been crafted in France under the name CIR-VIR ("Cirrhose Virale"). ${ }^{28,37,38}$ It has served to establish the benefits of screening intervals and HCC incidence along time, as well as to refine the HCC risk according to conventional and novel parameters. In a recent study, they have proposed an HCC risk stratification using simple clinical parameters, which should serve as a benchmark to compare data arising in studies assessing the HCC incidence after DAA therapy. $^{28}$

The Italian multicenter cohort from Veneto presented the incidence of HCC in HCV patients treated with DAA therapy in the last American Association for the Study of Liver Diseases meeting. ${ }^{41}$ As described there, they ruled out the presence of HCC by ultrasound before starting DAAs and then performed ultrasound screening every 6 months in all patients. They analyzed 3,075 patients, who were followed for 300.8 days (mean) from the start day of DAA treatment. The majority presented compensated cirrhosis or F3 (only 7\% Child-Pugh B) when starting DAA treatment. With half of the patients having less than 300 days of follow-up, they reported a $1.64 \%$ person/year incidence (95\% CI, 1.18-2.21). The authors concluded that the results were no different from that to be expected in untreated patients, but the expansion of the follow-up may further increase this figure.

The French CIR-VIR cohort $28,37,38$ will be instrumental in providing relevant information about incidence rate, time association, HCC pattern at diagnosis in compensated HCV, and the impact of DAAs in liver cancer development. This is a prospective cohort study that follows up patients with cirrhosis who undergo regular screening according to guidelines. It has raised a proposal to stratify patients according to different magnitudes of risk based on easily available clinical parameters (age $>50$ years, past excessive alcohol consumption, platelet count, gamma-glutamyl transferase, and nonsustained virological response during the study period). The group at higher risk is expected to have a one-year incidence of 3.15\%. Abstracts presented by the ANRS/Association Française des Enseignants de Français (AFEF) Study Group at the 2016 EASL annual meeting ${ }^{42}$ have reported an incidence of $18 / 1,000$ person/y during the first 6 months after DAA therapy; this is reduced by half after 12 months. With such a description, it is key to ascertain to what extent DAA therapy is associated with a peak in incidence in the following 12 months, or if the incidence has become very high at the time of DAA and the values after 12 months represent a real reduction. Because the cohort may have data about the tumor stage at detection over the last few years, the study will also inform about the potential aggressive profile of the DAA-associated cancers.

Interestingly, the Veneto cohort, which includes $27.7 \%$ noncirrhotic patients, describes a more aggressive HCC pattern at diagnosis after DAA treatment. A single nodule was registered in $48.8 \%$ and an infiltrative/more than three nodules in 39\% (a quarter of these presenting vascular invasion or extrahepatic spread), while in the CIR-VIR cohort with $100 \%$ cirrhotics the pattern was a single nodule in $69.6 \%$, up to two to three nodules in $19.8 \%$, and an infiltrative/more than three nodules in $10.8 \%$. This more aggressive profile coincides with our finding about HCC recurrence.

If the tumors are more aggressive, this should be due to faster tumor growth leading to a more advanced stage earlier in time. Hence, clinical and radiologic recognition should occur earlier than expected, more cases would be detected 
during the follow-up period, and this would translate in increased incidence. It could be argued that in some centers the screening expertise was not optimal and detection was done late. If this were the case, the suboptimal expertise would impair the HCC detection and its incidence would be underestimated.

A striking finding in several reports is the clearcut time association between DAA treatment and HCC emergence. ${ }^{15}$ This time association is key in pharmacovigilance programs, and it should be carefully assessed in all studies.

Studies of other cohorts of HCV cirrhotic patients treated with DAAs have been published. As mentioned earlier, the endpoint of these studies was not HCC development or the methods in place did not secure HCC screening and diagnosis following an established protocol that adhered to current practice guidelines. In addition, some studies of the same cohort such as the UK one have presented data using different follow-up periods. ${ }^{20,21}$ Foster et $\mathrm{al}^{21}$ and Cheung et $\mathrm{al}^{20}$ evaluated the same cohort of patients, but the initial time point in Foster et $\mathrm{al}^{21}$ was the day of DAA initiation, whereas in Cheung et $\mathrm{al}^{20}$ it was at the end of DAA treatment. This explains the discrepancy in their 6-month incidence $(5.4 \%$ and $4.2 \%$, respectively) and exposes the importance of the time-point definition when comparing different studies. Furthermore, Cheung et $\mathrm{al}^{20}$ compared DAA-treated patients with a cohort of untreated patients in which the information about baseline liver function was not reported. An Italian study in decompensated cirrhotics treated or not treated with IFN-based regimes describes a $3 \%$ incidence at 6 months. ${ }^{43}$ Even if a direct comparison between these cohorts is not robust, it reinforces a concern.

Additional results from separate studies and information from follow-up investigations in industry trials as well as population registries will provide the necessary information to fully elucidate this controversial issue.

The need to collect more data triggered the November 2016 Press Release from the European Medicines Agency. ${ }^{44}$ The Press Release outlines the Agency's need for more information from different sources to properly define the potential risk of cancer associated with the treatment of $\mathrm{HCV}$ using the new DAA agents. Interestingly, the acceptance of a potential risk of hepatitis $B$ virus (HBV) reactivation associated with DAA therapy even in patients with positive core antibody only (in whom the risk is very low) and the instruction to carefully monitor HBV reactivation during treatment was based on less data as compared with HCC emergence and has not been as controversial.

\section{The Immune Connection}

The immune system has the intrinsic ability to recognize tumor cell antigens and control cancer growth. ${ }^{45}$ Immune cells are continuously struggling with tumor cells, resulting in the establishment of a dynamic equilibrium in which tumor dormancy may be achieved. ${ }^{46}$ The presence of $\mathrm{T}$ cells within tumors is associated with a better prognosis, confirming the role of the immune response in maintaining subclinical tumor in the equilibrium state. ${ }^{47}$ Indeed, a fall of antigenic load (as may happen upon HCV eradication) promotes a hyporesponsive state of memory-helper T cells. ${ }^{48}$ The reports about $\mathrm{HBV}^{49}$ and herpes virus reactivation ${ }^{50}$ associated with DAA treatment strongly suggest a breakdown of immune surveillance as the main mechanism that might be involved in cancer emergence. Tumor immunerelated dormancy has been shown in metastasized tumor cells from early primary tumors, ${ }^{51}$ and immune surveillance controlling tumor dormancy uses effector immune pathways similar to those active during tumor destruction. All these data suggest that immunological changes related with the acute HCV clearance have a role in the emergence of cancer events.

Furthermore, tissue-associated macrophages are a major field of research as they are shown to influence tumor evolution and could become a target for therapeutic infiltration. Sorafenib has a marked effect on macrophages and it has been suggested that the benefits in survival may be in part mediated by immunomodulation. ${ }^{52}$ Finally, major hope has been placed in immunotherapy and following its success in other tumors, active research is now underway in HCC.

Altogether, it is clear that immune phenomena might be involved in the evolution of HCC. If we accept that immune surveillance is affected by the successful eradication of HCV replication, it could be that the same phenomena should have been registered with prior treatments based on IFN. However, this is not the case as all registries indicate that viral eradication under IFN-based regimes translates into a reduction of HCC incidence. The reason for such a difference is probably related to the kinetics of viral eradication that is faster under DAAs. Thus, it is appealing to hypothesize that the abrupt resolution of infection within days or weeks affects immune cell populations, which will no longer guarantee tumor cell destruction and consequently allow the wake-up of dormant cancer clones. In addition, IFN might also play a role in controlling tumor growth due to its antiproliferative action and activation of innate immune responses.

Tumor dormancy results from several conditions: immune surveillance controlling tumor outgrowth, hostile tumor microenvironment, or tumor cells being quiescent.

If immune cancer surveillance is distorted, a major concern about extrahepatic cancer development would become apparent. Chronic inflammation such as long-lasting HCV infection increases the risk of extrahepatic cancer and transformed cells may stay subclinical or even remain indolent for a long period. However, information about this issue is very limited $^{38}$; we should await more results based on large datasets.

In summary, several sets of data suggest there is an increased cancer risk in HCV patients successfully treated with the new DAAs. Although this may be seen as counterintuitive and not aligned with the expectations of patients and physicians, we need major epidemiological and clinical research that avoids the previous research flaws that may have affected some of the prior investigations. This will allow us to accurately define the risk and identify the patient profile that may be associated with this dismal event. 


\section{Abbreviations}

$\begin{array}{ll}\text { ANRS } & \text { French Agency of Research on AIDS } \\ \text { BCLC } & \text { Barcelona Liver Cancer Clinic } \\ \text { CirVir } & \text { Cirrhose Virale } \\ \text { DAAs } & \text { direct antiviral agents } \\ \text { EASL } & \text { European Association for the Study of the Liver } \\ \text { HBV } & \text { hepatitis B virus } \\ \text { HCC } & \text { hepatocellular carcinoma } \\ \text { HCV } & \text { hepatitis C virus } \\ \text { IFN } & \text { interferon. }\end{array}$

Conflicts of Interest

María Reig has received support from Bayer, BTG, and Gilead, attended conferences sponsored by Bayer, and is an advisor for Bayer. Zoe Mariño has received speaker fees from Abbvie, Gilead, Janssen. Xavier Forns has received unrestricted grant support from Abbvie and Gilead and is an advisor for Abbvie, Gilead, and Janssen. Jordi Bruix is a consultant for Gilead, Abbvie, Kowa, Bayer, BTG, Arqule, Terumo, BMS, Boehringer Ingelheim, Kowa, Novartis, OSI, Roche, and Onxeo.

\section{Financial Support}

María Reig received support in part from the Instituto de Salud Carlos III (PI15/00145). Xavier Forns received support in part from the Instituto de Salud Carlos III (PI15/ 00151). Jordi Bruix received grant support from the Instituto de Salud Carlos III (PI14/00962), AECC (PI044031), and WCR (AICR) 16-0026. Xavier Forns and Jordi Bruix received grant support from the Secretaria d'Universitats i Recerca del Departament d'Economia i Coneixement (2014 SGR 605 and 233), and from the Spanish Health Ministry (Plan Estratégico Nacional contra la Hepatitis C).

\section{References}

1 European Association for the Study of the Liver. EASL Recommendations on Treatment of Hepatitis C. J Hepatol 2016;66(1): 153-194

2 Poordad F, Lawitz E, Kowdley KV, et al. Exploratory study of oral combination antiviral therapy for hepatitis C. N Engl J Med 2013; 368(1):45-53

3 Ferenci P, Bernstein D, Lalezari J, et al; PEARL-III Study; PEARL-IV Study. ABT-450/r-ombitasvir and dasabuvir with or without ribavirin for HCV. N Engl J Med 2014;370(21):1983-1992

4 Feld JJ, Kowdley KV, Coakley E, et al. Treatment of HCV with ABT450/rombitasvir and dasabuvir with ribavirin. N Engl J Med 2014; 370(17):1594-1603

5 Kwo PY, Mantry PS, Coakley E, et al. An interferon-free antiviral regimen for HCV after liver transplantation. N Engl J Med 2014; 371(25):2375-2382

6 Foster GR, Afdhal N, Roberts SK, et al; ASTRAL-2 Investigators; ASTRAL-3 Investigators. Sofosbuvir and velpatasvir for HCV genotype 2 and 3 infection. N Engl J Med 2015;373(27):2608-2617
7 Curry MP, O’Leary JG, Bzowej N, et al; ASTRAL-4 Investigators. Sofosbuvir and velpatasvir for HCV in patients with decompensated cirrhosis. N Engl J Med 2015;373(27):2618-2628

8 Feld JJ, Jacobson IM, Hézode C, et al; ASTRAL-1 Investigators. Sofosbuvir and velpatasvir for HCV genotype 1, 2, 4, 5, and 6 infection. N Engl J Med 2015;373(27):2599-2607

9 Sulkowski MS, Gardiner DF, Rodriguez-Torres M, et al; AI444040 Study Group. Daclatasvir plus sofosbuvir for previously treated or untreated chronic HCV infection. N Engl J Med 2014;370(3): 211-221

10 Poordad F, Hezode C, Trinh R, et al. ABT-450/rombitasvir and dasabuvir with ribavirin for hepatitis $\mathrm{C}$ with cirrhosis. N Engl J Med 2014;370(21):1973-1982

11 Afdhal N, Reddy KR, Nelson DR, et al; ION-2 Investigators. Ledipasvir and sofosbuvir for previously treated HCV genotype 1 infection. N Engl J Med 2014;370(16):1483-1493

12 Jacobson IM, Gordon SC, Kowdley KV, et al; POSITRON Study; FUSION Study. Sofosbuvir for hepatitis C genotype 2 or 3 in patients without treatment options. N Engl J Med 2013;368(20): $1867-1877$

13 Lawitz E, Mangia A, Wyles D, et al. Sofosbuvir for previously untreated chronic hepatitis C infection. N Engl J Med 2013; 368(20):1878-1887

14 Calvaruso V, Craxì A. Why do I treat my patients with mild hepatitis C? Liver Int 2016;36(Suppl 1):7-12

15 Reig M, Mariño Z, Perelló C, et al. Unexpected high rate of early tumor recurrence in patients with HCV-related HCC undergoing interferon-free therapy. J Hepatol 2016;65(4):719-726

16 Bruix J, Takayama T, Mazzaferro V, et al; STORM investigators. Adjuvant sorafenib for hepatocellular carcinoma after resection or ablation (STORM): a phase 3, randomised, double-blind, placebo-controlled trial. Lancet Oncol 2015;16(13):1344-1354

17 Ikeda K, Kobayashi M, Kawamura Y, et al. Stage progression of small hepatocellular carcinoma after radical therapy: comparisons of radiofrequency ablation and surgery using the Markov model. Liver Int 2011;31(5):692-699

18 Buonfiglioli F, Conti F, Andreone P, et al. Development of hepatocellular carcinoma in HCV cirrhotic patients treated with direct acting antivirals. Paper presented at: European Association for the Study of the Liver: The International Liver Congress; April 1317, 2016; Barcelona, Spain. Abstract LBP 506. J Hepatol 2016; 64(2):S215

19 Conti F, Buonfiglioli F, Scuteri A, et al. Early occurrence and recurrence of hepatocellular carcinoma in HCV-related cirrhosis treated with direct-acting antivirals. J Hepatol 2016;65(4): 727-733

20 Cheung MCM, Walker AJ, Hudson BE, et al; HCV Research UK. Outcomes after successful direct-acting antiviral therapy for patients with chronic hepatitis $C$ and decompensated cirrhosis. J Hepatol 2016;65(4):741-747

21 Foster GR, Irving WL, Cheung MCM, et al. Cohort study of the impact of direct acting antiviral therapy in patients with chronic hepatitis C and decompensated cirrhosis. J Hepatol 2016;64(6): 1224-1231

22 Zeng Q-L, Li Z-Q, Liang H-X, et al. Unexpected high incidence of hepatocellular carcinoma in patients with hepatitis $C$ in the era of DAAs: too alarming? J Hepatol 2016;65(5):1068-1069

23 Zavaglia C, Okolicsanyi S, Cesarini L, et al. Is the risk of neoplastic recurrence increased after prescribing direct-acting antivirals for HCV patients whose HCC was previously cured? J Hepatol 2017; 66(1):236-237

24 Tsai P-C, Huang C-F, Yu M-L. Unexpected early tumor recurrence in patients with hepatitis $C$ virus-related hepatocellular carcinoma undergoing interferon-free therapy: issue of the interval between HCC treatment and antiviral therapy. J Hepatol 2017; 66(2):464

25 Kozbial K, Moser S, Schwarzer R, et al. Unexpected high incidence of hepatocellular carcinoma in cirrhotic patients with sustained 
virologic response following interferon-free direct-acting antiviral treatment. J Hepatol 2016;65(4):856-858

26 ANRS Collaborative Study Group on Hepatocellular Carcinoma. Lack of evidence of an effect of direct-acting antivirals on the recurrence of hepatocellular carcinoma: data from three ANRS cohorts. J Hepatol 2016;65(4):734-740

27 Sugimoto K, Kim SR, Kim SK, et al. Comparison of daclatasvir and asunaprevir for chronic HCV 1b infection with telaprevir and simeprevir plus peginterferon and ribavirin, with a focus on the prevention of occurrence and recurrence of hepatocellular carcinoma. Oncology 2015;89(Suppl 2):42-46

28 Ganne-Carrié N, Layese R, Bourcier V, et al; ANRS CO12 CirVir Study Group. Nomogram for individualized prediction of hepatocellular carcinoma occurrence in hepatitis $C$ virus cirrhosis (ANRS CO12 CirVir). Hepatology 2016;64(4):1136-1147

29 Kobayashi M, Suzuki F, Fujiyama S, et al. Sustained virologic response by direct antiviral agents reduces the incidence of hepatocellular carcinoma in patients with HCV infection. J Med Virol 2017;89(3):476-483

30 Petta S, Cabibbo G, Barbara M, et al; Italian Liver Cancer (ITA.LI.CA) Group. Hepatocellular carcinoma recurrence in patients with curative resection or ablation: impact of HCV eradication does not depend on the use of interferon. Aliment Pharmacol Ther 2017;45(1):160-168

31 Torres HA, Vauthey JN, Economides MP, Mahale P, Kaseb A. Hepatocellular carcinoma recurrence after treatment with direct-acting antivirals: first, do no harm by withdrawing treatment. J Hepatol 2016;65(4):862-864

32 Yang JD, Aqel BA, Pungpapong S, Gores GJ, Roberts LR, Leise MD. Direct acting antiviral therapy and tumor recurrence after liver transplant for hepatitis C-associated hepatocellular carcinoma. J Hepatol 2016;65(4):859-860. Doi: 10.1016/j.jhep.2016.06.023 Epub 2016 Jul 5

33 Toyoda H, Tada T, Takaguchi K, et al. Differences in background characteristics of patients with chronic hepatitis $C$ who achieved sustained virologic response with interferon-free versus interferon-based therapy and the risk of developing hepatocellular carcinoma after eradication of hepatitis. J Viral Hepat 2017. Doi: $10.1111 /$ jvh.12665

34 Minami T, Tateishi R, Nakagomi R, et al. The impact of directacting antivirals on early tumor recurrence after radiofrequency ablation in hepatitis C-related hepatocellular carcinoma. J Hepatol 2016;65(6):1272-1273

35 Cammà C, Cabibbo G, Craxì A. Direct antiviral agents and risk for HCC early recurrence: much ado about nothing. J Hepatol 2016; 65(4):861-862

36 Pol S, Bourliere M, Lucier S, et al; ANRS/AFEF HEPATHER study group. Safety and efficacy of daclatasvir-sofosbuvir in HCV genotype 1-mono-infected patients. J Hepatol 2017;66(1):39-47

37 Trinchet J-C, Bourcier V, Chaffaut C, et al; ANRS CO12 CirVir Group. Complications and competing risks of death in compensated viral cirrhosis (ANRS CO12 CirVir prospective cohort). Hepatology 2015;62(3):737-750

38 Nahon P, Bourcier V, Layese R, et al; ANRS C012 CirVir Group. Eradication of hepatitis $C$ virus infection in patients with cirrhosis reduces risk of liver and non-liver complications. Gastroenterology 2017;152(1):142-156.e2

39 Cabibbo G, Petta S, Barbàra M, et al; ITA.LI.CA study group. A metaanalysis of single HCV-untreated arm of studies evaluating outcomes after curative treatments of HCV-related hepatocellular carcinoma. Liver Int 2017. Doi: 10.1111/liv.13357

40 Alonso S, Riveiro-Barciela M, Fernandez I, et al. Effectiveness and safety of sofosbuvir-based regimens plus an NS5A inhibitor for patients with HCV genotype 3 infection and cirrhosis. Results of a multicenter real-life cohort. J Viral Hepat 2017;24(4):304-311

41 Romano A, Capra F, Piovesan S, Alberti Alncidence and pattern of 'de novo' hepatocellular carcinoma in HCV patients treated with oral DAAs. Paper presented at: 67th Meeting of the American Association for the Study of Liver Diseases: Liver Meeting; November 11-15, 2016; Boston, MA. Abstract 19

42 Carat F. Clinical outcomes in HCV-infected patients treated with direct acting antivirals-18 months-post-treatment follow-up in the French ANRS CO22 HEPATHER cohort study. Paper presented at: European Association for the Study of the Liver: The International Liver Congress; April 13-17, 2016; Barcelona, Spain. Abstract LBP 505. J Hepatol 2016;64(2):S215

43 Iacobellis A, Siciliano M, Perri F, et al. Peginterferon alfa-2b and ribavirin in patients with hepatitis $C$ virus and decompensated cirrhosis: a controlled study. J Hepatol 2007;46(2):206-212

44 European Medicines Agency. PRAC warns of risk of hepatitis B re-activation with direct-acting antivirals for hepatitis C. Available at: http://www.ema.europa.eu/ema/index.jsp?curl=pages/ news_and_events/news/2016/12/news_detail_002659.jsp\&mid= WC0b01ac058004d5c1. Accessed February 25, 2017

45 Fridman WH, Pagès F, Sautès-Fridman $C$, Galon J. The immune contexture in human tumours: impact on clinical outcome. Nat Rev Cancer 2012;12(4):298-306

46 Quesnel B. Cancer vaccines and tumor dormancy: a long-term struggle between host antitumor immunity and persistent cancer cells? Expert Rev Vaccines 2006;5(6):773-781

47 Galon J, Mlecnik B, Bindea G, et al. Towards the introduction of the 'Immunoscore' in the classification of malignant tumours. J Pathol 2014;232(2):199-209

48 Dalai SK, Khoruzhenko S, Drake CG, Jie CC, Sadegh-Nasseri S. Resolution of infection promotes a state of dormancy and long survival of CD4 memory T cells. Immunol Cell Biol 2011;89(8): 870-881

49 Collins JM, Raphael KL, Terry C, et al. Hepatitis B virus reactivation during successful treatment of hepatitis $C$ virus with sofosbuvir and simeprevir. Clin Infect Dis 2015;61(8):1304-1306

50 Perelló CS, Fernández-Carrillo C, Londoño M-C, et al. Reactivation of herpes virus in patients with hepatitis $C$ treated with directacting antiviral agents. Clin Gastroenterol Hepatol 2016;14(11): 1662-1666. Doi: 10.1016/j.cgh.2016.05.016. Epub 2016 May 20

51 Manjili MH. The inherent premise of immunotherapy for cancer dormancy. Cancer Res 2014;74(23):6745-6749

52 Sprinzl MF, Reisinger F, Puschnik A, et al. Sorafenib perpetuates cellular anticancer effector functions by modulating the crosstalk between macrophages and natural killer cells. Hepatology 2013; 57(6):2358-2368 